\title{
Design Science Research for Business Process Design: Organizational Transition at Intersport Sweden
}

\author{
Mikael Lind ${ }^{1}$, Daniel Rudmark ${ }^{2}$, and Ulf Seigerroth ${ }^{3}$ \\ ${ }^{1}$ School of Business and Informatics, \\ University of Borå, \\ SE 51090 Borås, Sweden \\ 2 Innovation Lab, \\ University of Borås, \\ SE 51090 Borås, Sweden \\ ${ }^{3}$ School of Engineering, \\ Jönköping University, \\ SE 551 11Jönköping, Sweden
}

\begin{abstract}
Business processes need to be aligned with business strategies. This paper elaborates on experiences from a business process design effort in an action research project performed at Intersport Sweden. The purpose with this project was to create a solid base for taking the retail chain Intersport into a new organizational state where the new process design is aligned with strategic goals. Although business process modeling is concerned with creating artifacts, traditionally information systems design science research has had little impact on research on business process models. In this paper, we address the question of how design science research can contribute to business process design. Three heuristic guidelines for creating organizational commitment and strategic alignment in process design are presented. The guidelines are derived from the successful actions taken in the research project. The development of these guidelines is used as a basis to reflect upon the contribution of design science research to business process design.
\end{abstract}

Keywords: Design science research, business process design, action research, co-design.

\section{Introduction}

A significant part of science has always been to create abstractions for different purposes. Rosenblueth and Wiener (1945) once stated that no substantial part of the universe is so simple that it can be grasped and controlled without making abstractions. A model is usually a representation of a phenomenon for a certain purpose (Matthews 2007). In this paper, the role of models and how to design models is elaborated in the context of business process design where process models serve as a transformation vehicle in such a design process. On a scientific level, which also affects process design, there is still a debate about the role of models and the required 
characteristics of models in order to contribute to peoples' understanding and development of a common knowledge base (Matthews 2007).

Modeling and business process design has been acknowledged as critical for the development of business practices and information systems (Harmon 2010). Business processes have received significant attention in conceiving business practices due to their focus on clients and other stakeholders (e.g., Davenport 1993; Davis 2001; vom Brocke and Thomas 2006). Business process models are used for several purposes (see Bandara et al. 2006; Harmon 2010) such as describing existing practice (AS-IS) and designing the future (TO-BE), as well as determining historical chains of events. Based on this, there is a need to elaborate on the role of models and their usage since this will affect both the design and implementation of the models. This is motivated by the tendency of practitioners within the IS field to engage in conceptual modeling, focusing on business processes for the purpose of analysis, design, and evaluation of information systems (Davies et al. 2006). As an object, business process models can be regarded as tangible patterns of actions performed by people, often supported by artifacts, within and between organizations (Goldkuhl and Lind 2008). Process modeling and process models are often considered a part of the area of enterprise modeling. One way to conceptually describe this area is to divide it into three sections: modeling product (language and notation), modeling process (guidance), and modeling tool (support) (Stirna and Kirikova 2008). Historically, significant emphasis has been given to languages and notations for modeling (e.g., Scheer and Nüttgens 2000; Tolvanen and Lyytinen 1992), but less research has been performed in relation to guidance for how to design models, how to use models, or how the actual modeling should be performed.

Design science research is concerned with the artificial (Simon 1996). The rationale for undertaking design science research is to develop knowledge about how to construct artifacts that address an unsolved problem space. In process design, business process models are central - both as a part of the process and as the product of business process design. Since these process models are artifacts, design science research could be an interesting approach to address how to construct process models (e.g., Hevner et al. 2004; van Aken 2004). To our knowledge, the business process modeling research community has yet to adopt and evaluate design science research as a mode of inquiry. The research reported in this paper is consequently driven by how to design business processes by using process models as a transformation vehicle into a future state. Specifically, since the research conducted is concerned with interventional in situ design of business processes, the research must handle both the social construction of a possible future as well as the strategic goals of the organization. Hence, the research question posed in this paper is, how can design science research contribute to business process design? To explore this question, an action research project has been performed where the design of the business processes of the Swedish part of Intersport has been the focus. One should note that there has been a debate whether action research and design science research is a good blend (Cole et al. 2005) or if their relationship is more complicated (Iivari and Venable 2009). Hence, this research has the potential to yield several contributions. During the Intersport process design project, design guidelines for process design have been developed using the design science research literature. In this paper, we use these 
guidelines for reflecting upon the use of design science research as a means to develop knowledge about business process design.

The rest of the paper is organized as follows. Following this section, design science research as an approach for business process modeling is introduced, followed by the introduction of used kernel theories in the case. These kernel theories address both pragmatic perspectives on business processes and our view on collaborative business process modeling. This is followed by descriptions of the Intersport case and the evolving guidelines for business process design. The discussion then focuses on experiences made from using design science research in business process design. The paper concludes with some reflections related to performing business process design endeavors in using design science research.

\section{Design Science Research for Business Process Design}

In the design science research paradigm, knowledge and understanding of a problem domain and its solutions are achieved through scientifically grounded design and evaluation of artifacts (Hevner et al. 2004; Gregor and Jones 2007). Thus, at the core of design science lies the generation of knowledge about how to design artifacts that solve problems that so far have not been solved (to some extent), and where these artifact(s) may be used to improve an unwanted situation (Simon 1996).

Since many practitioners in the IS field are concerned with designing (artifacts and/or actions), design science research has been brought forward as a response to the various calls for practitioner relevance (see Benbasat and Zmud 1999; Roseman and Vessey 2008). The usefulness of design science research has been argued in a range of application areas related to information systems: technology-oriented artifacts (Hevner et al. 2004; Nunamaker et al. 1991), socio-technical systems (Markus et al. 2002), organizations (Romme 2003), and managerial action (Van Aken 2004).

A core concept within design science is the artifact. Our conception is that an artifact is something that is created by humans which cannot exist without human involvement, both in design and interpretation, and as something that can be instantiated with physical and/or social properties (Lind et al. 2008).

In the context of this paper, the problem of how to design business processes is conceived as a class of problems addressing questions including

- How can models be used as an essential transformation vehicle to successively reach a desired state?

- What kind of models should be used?

- Which different versions of models exists during process design?

- What cooperation patterns should be emphasized during such endeavor?

However, this class of problems (business process modeling for business process design) suggests that artifacts alone cannot produce the type of results necessary to achieve the sought-after organizational transition. To be able to put scientific validity claims on such research findings, it must also address the use of other theoretically informed actions in cohesion with the artifacts being constructed. Put in other words, in business process modeling, actions (van Aken 2004) and artifacts (Hevner et al. 2004; March and Smith 1995; Nunamaker et al. 1991) constitute inseparable parts that 
the design science researcher is obliged to recognize. This means that design science research should be concerned with two principal parts: developing knowledge about both the constituents of business process models (artifacts) and the complementary actions that need to accompany these models in order to reach the desired transition. In this paper, we will put stronger focus on the actions than on the constituents of the artifacts (business process models) due to the need for knowledge related to the modeling process (see above).

Design science research is carried out by an ongoing interplay between two major activities: build/design and evaluate. By building or designing the researchers are inscribing kernel theories into the artifact(s) and hence demonstrating that the artifact can be constructed (Gregor 2006; Hanseth and Lyytinen 2004; Walls et al. 1992). In the case of business process design, the researcher must further be concerned with applying principles informed by kernel theories to connected actions (van Aken 2004), as described earlier.

The next principal phase is evaluating (Hevner et al. 2004), where the design is measured against some metrics, showing whether (or to what extent) the problem has been solved and which new scientific theories that can be formulated (March and Smith 1995). In the case of business process modeling, we argue that it is necessary to design and evaluate in an authentic environment or, put in words of van Aken (2004), that the design is both field-tested and grounded. This is true since we believe that performing relevant research on tangible phenomena such as collaborative construction of an organization's future (and the stakes associated with such a process) is a bad fit with a more controlled environment. With this backdrop on our conception of design science research and how business process design may be inquired through it, we next present our case were this research approach has been applied. We start with putting forward used kernel theories.

\section{Used Kernel Theories for Business Process Design}

\subsection{Transition through Business Process Design: A Pragmatic Perspective}

Business process modeling has been acknowledged as a means for management of processes by several scholars (e.g., Günther et al. 2008; van der Aalst et al. 2007). Business process management (BPM) has traditionally adopted a horizontal rather than vertical view on the division of labor and has its origin in both total quality management (TQM; Harrington 1991) and business process reengineering (BPR; Davenport 1993; Hammer 1990). Basically, BPM can be seen as an industrial view on business processes, where input (raw material) is transformed into output (finished products). As advocated by Keen and Knapp (1996) there are, however, other conceptions of business processes.

One complementary conceptual base for business processes is a pragmatic foundation (e.g., Recker 2007) — rooted in American pragmatism (see Dewey 1922)— which ontologically puts action as the core of business processes. In order to expand the scope beyond transformational dimensions of business processes, the notion of business acts is conceived as the basic unit of analysis (see Lind and Goldkuhl 2003). 
A business act can be a speech act (communicative act) (e.g., Searle 1969) or a material act.

Business acts build upon the notion of social action. An organization consists of humans, artifacts (along with other resources), and the actions performed. Humans (often supported by artifacts) perform actions on behalf of the organization (Ahrne 1994). Actions are both performed within the organization-internal acts-and toward other organizations (e.g., customers or suppliers) —external acts. Humans act in order to achieve ends (von Wright 1971). Human action often aims at making material changes. However, humans do not only act in the material world; they also act communicatively toward other humans. Human actions are about making a difference, where such a difference can have an impact in the social world as well as in the material world. As described in Lind and Goldkuhl (2003), a business act is defined as the performance of communicative and/or material acts by someone aimed at someone else. By using business acts as the basic unit of business processes, transformative as well as coordinative and interactive dimensions of business processes may be included (Goldkuhl and Lind 2008).

Transformative dimensions denote a focus on the transformation of deliverable products, in structured and sequenced ways, from base products (raw material) to refined products. Coordinative dimensions mean that business processes involve important coordination mechanisms for the establishment, fulfillment, and assessment of agreements between involved stakeholders (e.g., suppliers and customers). Interactive dimensions are the special case of coordination in which the actors' performance of communicative and/or material exchanges is focused. As proposed by Goldkuhl and Lind (2008), these two views need to be combined in an integrative view where coordination (including interaction) and transformation form an integrated texture of actions. In this sense, assignment processes become superior in relation to transformation processes.

The modeling process is constituted of asking questions and giving answers to these questions through documentation in models. Business process models are thus built upon modeling languages (see Schuette and Rotthowe 1998); that is, concepts and notation to be used. The view on business processes, as discussed above, will in this way influence the content of the models being generated. The underlying view on business processes could thus be seen as a reference model (see Thomas 2005) to be used in generating situational models covering particular areas of concern. In this paper, we are especially interested in the use of process models for the purpose of taking a business practice from one state to another - a transition. In such a transition process it is important to focus on essential characteristics of the future in the business practice through the use of a rich repertoire of process concepts. This concerns both resulting models to be used for describing a future state (TO-BE) as well as intermediary models used to develop an understanding about the characteristics of the future state. The gap between existing practice (AS-IS) and a desired future state described in the resulting models form the basis for specifying an action plan covering overall and detailed actions to arrive at a future desired state. 


\subsection{Collaborative Process Modeling for Strategic Alignment and Organizational Commitment}

The models that are produced during business process modeling should be aligned with intended business plans and strategies. To meet this challenge, there is a need to understand and to be able to handle the complexity that exists in terms of different aspects or conceptual domains in the business (Langefors 1973; Lankhorst. 2005; Vernadat 2002).

Lankhorst (2005) exemplifies these multiple enterprise aspects with five heterogeneous architectural domains (i.e., information architecture, process architecture, product architecture, application architecture, and technical architecture) that are related to each other and the need for them to be aligned in an integrated way. The challenge is not to deal with isolated domains but to go beyond the individual models and to cope with how they are related to each other on different levels and how, as parts in the total picture, they support different strategic goals. One way to achieve alignment between strategies, models, and, in the end, IS/IT architectures is to adopt a co-design approach (Lind et al. 2007; Liu et al. 2002; Rittgen 2007) during the development of the models.

The process of developing models is about capturing different people's knowledge about diverse parts of business processes and different levels. Based on a socialconstructive view on knowledge creation, business process models will be an issue of design since the research is concerned with what does not yet exist (Nelson and Stolterman 2003). Knowledge and commitment between people about the future is created through their interaction (i.e., people are acting socially in relation to each other). Throughout the process different versions of models (solutions) coevolve with the understanding of the problem (see Cross 2007; Purao 2002). This means that different roles need to be involved in process design, thereby constructing a joint view of the object in and of the design. One way to conceive such a process is to regard it as a co-design process (Lind et al. 2008) in which a number of views of reality coexist to be used for exploring solutions and the problem domain from different viewpoints. This co-innovative approach is closely related to the streams of Web 2.0 (Lind and Forsgren 2008) in which clients are engaged in collaborative processes of design (see Albinsson et al. 2007; Lind et al. 2007). Co-design as a design approach was originally coined by Forsgren (see Lind et al. 2008), who proposed a co-design framework as a multi-stakeholder model in which all stakeholders concerns, related to a certain co-design situation, are taken into consideration by either inviting, or considering, perspectives of diverse stakeholders. Measurement scales and ideals are co-constructed by engaged stakeholders and perspectives driven by future-oriented returns.

The motivation for a co-design approach to process design is to simultaneously work with several different stakeholders in a collaborative way to avoid conceptual deviations between strategic plans and models on different levels. The necessity of such a collaborative approach to process modeling has also been put forward by vom Brocke and Thomas (2006). They claim that relevant stakeholders in a certain modeling situation must be identified and efficient ways of coordination between 
them needs to be established. Much of the discourse related to strategic alignment is based on the framework by Henderson and Venkatraman (1999), who put forward four dimensions and their strategic fit to each other. Many of these dimensions are elaborated on through modeling and different models are used as an instrument to express how to achieve alignment and competitive advantage. In this paper, our basic assumption is that different types of process models can serve as a vehicle for realization of strategic business plans.

Business process models need to be a part, and the result, of people engaging in cocreating processes that are aligned with business strategies. In this approach an infinite number of views of reality may be designed based on the intention of the participators in the process. This type of collaborative design research is not stressed in the seminal information systems design science research frameworks (Hevner et al. 2004; March and Smith 1995; Nunamaker et al. 1991; van Aken 2004). Such an approach means that people in the environment and researchers jointly create artifacts (business process models) and collaboratively develop an understanding of the problem to be solved.

\section{Applying Design Science Research in Business Process Design: The Transition at Intersport Sweden}

\subsection{Project Background}

In this action research project, the main task has been to design Intersport's future business processes (for a description of the case and models produced, see Lind and Seigerroth 2010a). Intersport is a specialized, franchise-concept retail chain for sports and recreation. Intersport Sweden is part of the Intersport International Corporation (IIC), which is the world's largest sports retail chain with more than 4,900 stores in 32 countries.

The motivation of this project stems from Intersport Sweden initiating an extensive change program to redesign their business model in order to meet future needs and to create a competitive advantage in retail for sports and recreation. The core of the change process at Intersport is the transition from being a wholesale dealer with more or less independent stores to take an overall responsibility for the entire value chain (i.e., to become both retailer and wholesaler). In this sense, the scope of the business process design project covered the value chain spanning several organizations. This change process, called wholesaler-business development-retailer (WBR), describes a new vision for business areas (conceptual, strategic, and operative) that should be up and running in 2013.

The business process design in this case is meant to define Intersport Sweden's business practice for activities, results, prerequisites, work procedures, cooperation procedures, communication principles, roles, and responsibilities on different abstraction levels. The focus for the project has been to design Intersport's business model for 2013. Based on a new business strategy, business process models were designed to involve the people affected by the design. For Intersport, this covers everything-from strategic planning to products and services in use by their 
customers and ways to satisfy customer needs. Examples of new business principles in WBR are

- The responsibility for supplying and filling the stores with products is moved from the stores to a central organization at Intersport

- A shift in focus from a product structure to concepts that include more than the physical products

- The coordination and distribution of both Intersport's own and external brands should be done in a uniform way

- Intersport should have control of more than 80 percent of the total collections in all stores (base collection and category collections)

- A shift from stores ordering products early to early planning with late central distribution of collections

- A central retail function with responsibility for the total value chain

Through these changes, Intersport wants to strengthen its position by adopting a retail focus with centralized management and coordination. In combination with this Intersport is also moving from a focus on products and purchases to a focus on concepts and sales. The external attraction should increase in the value chain through development and clarification of Intersport's concepts, clarity in marketing, and focus on the customer. The aim is also to increase the internal efficiency through development of logistics and cost programs.

In the following sections, we present how we have developed three guidelines for business process design and how these guidelines are presented.

\subsection{Research Methodology: The Process of Deriving Guidelines}

Our choice of method was action research, a method that has proven to be useful in a certain type of research setting (see Lindgren et al. 2004). Action research has been described as a research method suited to study technology in a human context (Baskerville and Wood-Harper 1996), which is a core focus in the IS discipline. Our aim has been to investigate how design science research can contribute to business process design. We rely on the arguments presented by Lindgren et al. (2004), based on Mathiassen (2002, pp. 441): "Merely studying a real-world problem without assisting to resolve or ameliorate it is perceived as unhelpful. In other words, action researchers see it as their responsibility to assist practitioners by not only developing but also applying knowledge."

Validity claims concerning our contribution to the scientific body of knowledge are in accordance with multi-grounded theory (MGT) (Goldkuhl and Cronholm 2003): that the knowledge becomes internally, empirically, and theoretically validated. MGT is a reaction to grounded theory and it is more a pure inductive approach. MGT is a process for theory development. If a pragmatic view on knowledge is adopted, the result of an MGT process is knowledge as practical theories on the level of scientific body of knowledge. The combination of action research and MGT has made it possible for us to make contributions ("knowing through building," Purao et al. 2008, p. 5) to local practice (process models) in parallel with the development of scientific knowledge (guidelines for business process design).

In the spirit of action research, we have acted as intervening and co-designing observers at Intersport. Observations of the effects of performed acts and people's 
behavior have been the main sources of empirical input. The total set of empirical sources that act as our base for development of the guidelines are

- Project minutes and research notes from modeling sessions, meetings, and presentations in the practical inquiry at Intersport.

- Project minutes and research notes from other meetings concerning planning, coordination, assessment, and analysis of the practical inquiry.

- Project documentation (text, models, final report, etc.) as a result of actions performed in the practical inquiry in the local practice at Intersport. The final report was a project delivery with the prime purpose of presenting the newly designed business processes.

- Existing organizational documents from Intersport that describe existing and future practices (e.g., the new business, plan, organizational structure, etc.).

In addition, the personal knowledge-the impressions and experiences-we developed during the practical inquiry has been used as an empirical source.

The data collected were used in deriving the guidelines for business process design by conceptualizing experiences from the process design in local practice. The guidelines have been justified as multi-grounded according to Goldkuhl and Cronholm (2003). This means that we, in the development process, have gone through steps of multi-grounded theory in terms of theory generation (formulation of guidelines) and explicit grounding (test and evaluation of the guidelines).

\subsection{Result: Evolving Design Guidelines for Business Process Design}

In this section we present three guidelines for business process design based on the project. These guidelines are the result of a reconstruction of actions performed in this process design endeavor where we conceive these guidelines as the result of successfully conducted actions in the project.

Guideline 1: Extensive stakeholder involvement for establishing commitments. The process design described in this paper was performed through collaborative modeling where different organizational roles (stakeholders) have been involved in the design of a future state. The representation of people from Intersport in the project covered both new roles as a result of recruitment based on the new business plan as well as existing roles, which were preserved in the organization. The future design is governed by joint creation of business process models on different levels. The involvement of a multitude of stakeholders in the design conversation is one of the main pillars in co-design (Lind et al. 2008). The involved stakeholders in this case were (1) the CEO and executive management, (2) middle management (head of retail, head of logistics, etc.), and (3) operative personnel within different areas. Based on these categories, there was also a mixture of newly recruited people and personnel representing the existing organizational structure. These different stakeholders were mainly involved in design conversations according to the following division:

- $\quad$ Principle oriented design dialogue together with CEO and executive management.

- Design oriented modeling seminars together with concerned roles of delimited parts of the practice. This was mainly performed with middle management and operative personnel, but also partly with executive management. 
- Design oriented modeling seminars together with concerned roles of crosssectional parts of the practice. This was mainly performed together with middle management and operative personnel, but also partly with executive management.

- Validation as a part of the design dialogue and the modeling seminars and as explicit activities in dedicated meetings/presentations.

In the design project at Intersport, the evolving process models served as common ground for communication where different aspects of the new business logic were elaborated and on which the participating parties created a commitment to the evolving process design. This commitment concerned two aspects: a commitment of how to view the future of the practice (with its different parts), and a commitment from each stakeholder to engage in the realization of the depicted structure. One empirical proof for the first aspect is that all stakeholders signed the final report. By involving different stakeholders, the aim of the co-design process was to determine pros and cons, as well as determine new ideas and views in relation to the design (Lind et al. 2008). The resulting models of the process design are to be regarded as agreements among the involved stakeholders in which different stakeholder views have been taken into consideration and valued in the modeling process.

Engagement in the modeling sessions could differ from being active in discussions to actually, through drawings, giving suggestions for process design on a whiteboard or modeling sheet. In addition to this, and as mentioned earlier, the evolving process design was continuously sent to other stakeholders within Intersport for validation and response.

Guideline 2: Initial middle-out for organizational engagement. In this project, three types of models (main, principle, and detailed) have been used to represent process design on different levels of abstraction. The relative distribution over time of these three models is presented in Figure 1.

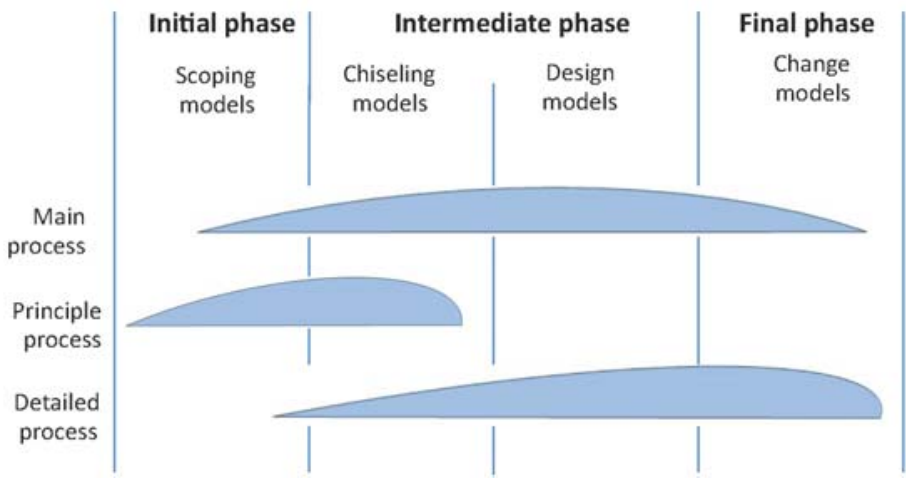

Fig. 1. The Roles of Different Artifacts

The final result from the project was to develop process descriptions on two levels, main process and detailed process. However, we did not start the work with these two types of models. During the initial modeling sessions, the main process model was regarded as too abstract, while in the detailed process model we got stuck in details. Hence we started to work with an intermediate level (principle process) that addressed 
principles in the new business model at the same time that we, during the modeling sessions, were able to understand the major consequences of the principles for further detailed design. This principle process, then, for the first half of the project, served as a bridge between the main process model and the detailed process models. In addition to the modeling sessions, the principle model also became the initial instrument for talks with the CEO and executive management, both for validation and to give new input to the subsequent modeling sessions. As can be seen in Figure 1, the principle model had served its purpose when the other two models evolved to a state where the relation between these two models became clear. At this stage, it became clear how the new business model was instantiated on the main process level and how these principles were instantiated in the detailed process models. The design of the main and detailed processes then evolved in parallel. The case shows that the principle process model (middle-out rather than top-down or bottom-up) is an important vehicle to engage and commit stakeholders in the development of the main process model and the detailed process models. Hence, this principle process model served as a bridging facilitator during the early stages of the project.

Guideline 3: Start addressing the core business and the rest will follow. As described above, different models on different levels have continuously been designed and refined throughout the project. As claimed earlier, different process models were needed to capture different aspects to pinpoint certain design results (business states) on different levels of granularity. Building on pragmatic (Lind and Goldkuhl 2003) foundations for understanding, the evaluation and design of business processes were elaborated in three essential process dimensions during the process design:

- Transformation-the refinement of the basis for finished products; the core business processes

- Coordination-the governance and management of the transformation

- Interaction - the interplay between people/organizations and artifact

We could empirically validate all three dimensions when we started to work with the translation of Intersport's new business plan into design of new business processes. For instance, during the modeling sessions, when people started to discuss how different matters on an operative level should be performed (transformation), the need to deal with governance, management, and interaction became an issue of the design. These issues (coordination and interaction) were captured in the models and emerged as more and more relevant as the models matured in their transformational dimension.

In the analysis of the case, we explored the three types of models that were designed in the project (main process model, principle process model, and detailed process model) in relation to their role (none, partly, or dominate) during different phases (see Table 1). The table is horizontally divided into the phases and vertically divided into the three core process dimensions.

As can be seen in Table 1, the role of the different dimensions (i.e., transformation, coordination, and interaction) has evolved during the phases of the project. One can note that the transformative dimension has been important during all phases of the project while the interactive dimension of the models is suppressed until the latter phases. This became quite clear when we analyzed different versions of the models 
and how the content of the models had evolved in the project. The main reason for this evolution of the process dimensions is that we needed to reach very detailed descriptions before it was meaningful to address which organizational roles should be responsible for and involved in different parts of the process. Similarly, the coordinative dimensions were only briefly addressed in the early phases and they were not fully developed until the latter phases of the project. There was a need to develop transformational process knowledge in order to be able to address what to coordinate. It is also important to note that in order to achieve "usable" design, all three dimensions (i.e., transformation, coordination, and interaction) needed to be elaborated and described.

Table 1. Different Models and the Roles of Process Dimensions during Different Phases of the Project

\begin{tabular}{|c|c|c|c|c|}
\hline \multirow[b]{2}{*}{$\begin{array}{l}\text { Model Type/ } \\
\text { Aspect }\end{array}$} & \multirow{2}{*}{$\begin{array}{c}\text { Initial Phase } \\
\text { Scoping } \\
\text { Models }\end{array}$} & \multicolumn{2}{|c|}{ Intermediate Phase } & Final Phase \\
\hline & & $\begin{array}{l}\text { Chiseling } \\
\text { Models }\end{array}$ & $\begin{array}{c}\text { Design } \\
\text { Models }\end{array}$ & $\begin{array}{l}\text { Change } \\
\text { Models }\end{array}$ \\
\hline Transformation & $\begin{array}{l}\text { Main: Part } \\
\text { Princ: Dom } \\
\text { Detail: Dom }\end{array}$ & $\begin{array}{l}\text { Main: Dom } \\
\text { Princ: Dom } \\
\text { Detail: Dom }\end{array}$ & $\begin{array}{l}\text { Main: Dom } \\
\text { Princ: N/A } \\
\text { Detail: Dom }\end{array}$ & $\begin{array}{l}\text { Main: Dom } \\
\text { Princ: N/A } \\
\text { Detail: Dom }\end{array}$ \\
\hline Coordination & $\begin{array}{l}\text { Main: Part } \\
\text { Princ: Part } \\
\text { Detail: None }\end{array}$ & $\begin{array}{l}\text { Main: Part } \\
\text { Princ: Part } \\
\text { Detail: Part }\end{array}$ & $\begin{array}{l}\text { Main: Dom } \\
\text { Princ: N/A } \\
\text { Detail: Dom }\end{array}$ & $\begin{array}{l}\text { Main: Dom } \\
\text { Princ: N/A } \\
\text { Detail: Dom }\end{array}$ \\
\hline Interaction & $\begin{array}{l}\text { Main: None } \\
\text { Princ: None } \\
\text { Detail: None }\end{array}$ & $\begin{array}{l}\text { Main: Part } \\
\text { Princ: None } \\
\text { Detail: Part }\end{array}$ & $\begin{array}{l}\text { Main: Part } \\
\text { Princ: N/A } \\
\text { Detail: Dom }\end{array}$ & $\begin{array}{l}\text { Main: Part } \\
\text { Princ: N/A } \\
\text { Detail: Dom }\end{array}$ \\
\hline
\end{tabular}

\section{Discussion: Design Science Research and Business Process Design}

\subsection{The Validity of Suggested Guidelines}

As claimed in the introduction of this paper, in BPM a lot of emphasis has historically been put on the constituents of models. In this paper, a stronger focus has instead been put on guidelines to assist in arriving at valid models. In design science research projects, there is a constant movement between the general and the specific (e.g., kernel theory-design-design theory) where the resulting, general design theory is based on the experiences gained in evaluating the more specific design. However, working in a specific and authentic setting, factors other than those reported in this essay influenced the final result, and vice versa. Reuse of these guidelines does not automatically depict commitment and alignment. Nevertheless, we strongly believe the practical utility claims of such knowledge could still be argued: "One might compare this contribution with one of a well-designed route, drawn on a good map for a South Pole expedition. It is a valuable asset to realize eventual success (reaching the South Pole and returning home safely), but success is not guaranteed" (van Aken 
2004, p. 12). When addressing guideline validity, they are demonstrated locally as in the case above but we argue that other factors further strengthen their validity.

- Guideline 1: Extensive stakeholder involvement for establishing commitments. This guideline stems from previous collaborative design work in other domains, where the co-design approach has proved useful (Lind et al. 2007; Liu et al. 2002; Rittgen 2007). In our case, we wanted to explore whether the approach could be useful in establishing organizational commitment in process design.

- $\quad$ Guideline 2: Initial Middle-Out for Organizational Engagement. This guideline emerged through the work during process design and is not directly derived from any kernel theory. This also means that this finding is potentially quite novel, but needs, in the spirit of multi-grounded theory, further grounding both theoretically and empirically.

- Guideline 3: Start addressing the core business and the rest will follow. This directive has its roots from prior pragmatic research in business process modeling based on several research projects (Goldkuhl and Lind 2008). However, this knowledge has not been presented previously as heuristic prescriptions in a design science research manner and its temporal dimension was found through the design inquiry.

\subsection{Framing Business Process Design as Action and Design Science Research}

During the design process performed at Intersport, a combination of research components has been applied (design science research being one). The process design has had a focus on design and validation of business models as artifacts, which have evolved, based on business demands and the utilization of essential categories derived from used kernel theories (the knowledge base). Both action research and design science research express the need for performing theoretically informed actions during research. Traditionally, action research has a strong focus on organizational change while design science research puts emphasis on evolving artifacts (properties of the artifacts and actions for arriving at desired artifacts). The action research tradition hence fails to properly address the theory-informed construction of artifacts (see Lindgren et al. 2004) while design science research does not intrinsically cover organizational change. In this setting, we found van Aken (2004) to be a particularly useful bridge between management action research and the more artifact-oriented IS literature in the field. In other words, even though the research performed and reported on in this paper has been performed in an action research setting, we still believe, in the spirit of Walls et al. (1992), that the knowledge presented in IS design science research gave us as researchers a more nuanced toolbox to address process design research. The division between artifact construction and evaluation (March and Smith 1995), the knowledge base, and the environment (Hevner et al. 2004) has helped us in structuring and paying attention to essential processes for this knowledge development and resulted in the three guidelines for business process design presented above.

\section{Conclusions}

In this paper, we have presented findings based on a process design project performed in a retail chain setting with the purpose of engaging people in describing and 
becoming committed to a future state as a means for the implementation of a new business model. In this setting, a business process design was performed as a step to transform a new business plan into detailed and comprehensive business process models.

On the basis of experiences gained from conducting this project as an action research endeavor, we have addressed the question of how design science research can contribute to business process design. From our experiences in this project, we believe the contribution of design science research is two-fold.

1. Since we believe that the nature of the problem domain in this paper (process design for organizational commitment and strategic alignment) requires that the design and evaluation of artifacts is performed in a naturalistic environment (Iivari and Venable 2009), iterating different versions of artifacts requires intervention. However, since action research is not designed to construct artifacts, importing such research constructs (e.g., kernel theory-design-evaluate) from the design science research approach makes the design process researcher more versatile. It does so by providing the researcher the ability to develop artifactoriented knowledge through theory-ingraining, as demonstrated in the case. By using these design science research components, new knowledge dimensions on process design can be developed, such as guideline 2 and the temporal dimension of guideline 3 .

2. As stated at the beginning of the paper, research on process design has mainly focused on the constituents of models. Considering the three guidelines put forward in this paper, we have found clear indications that research on process design in a design science mode might serve as a vehicle in addressing both the gap in the theoretical body of knowledge (how to produce models) as well as practitioner relevance through practical guidelines. These validity guidelines remains to be evaluated by practitioners in future studies.

The knowledge endeavor reported in this paper is to be seen as a step toward combining action research and design science research for collaborative modeling using co-design with the purpose of supporting organizations in their transition by using business process modeling. This approach has also been shown to be useful as a mean to ensure alignment between the new strategic business plan and the actual design of the new business process(es). This alignment dimension will be elaborated in a forthcoming article.

\section{References}

Ahrne, G.: Interaction Inside, Outside and Between Organization. Sage Publications, London (1994)

Albinsson, L., Lind, M., Forsgren, O.: Co-Design: An Approach to Border Crossing, Network Innovation. In: Cunningham, P., Cunningham, M. (eds.) Expanding the Knowledge Economy: Issues, Applications, Case Studies, vol.4, Part 2, pp. 977-983. IOS Press, Amsterdam (2007)

Bandara, W., Gable, G., Rosemann, M.: Business Process Modeling Success: An Empirically Tested Measurement Model. In: Proceedings of the 27th International Conference on Information Systems, Milwaukee, WI (2006) 
Baskerville, R.L., Wood-Harper, A.T.: A Critical Perspective on Action Research as a Method for Information Systems Research. Journal of Information Technology (11), 235-246 (1996)

Benbasat, I., Zmud, R.W.: Empirical Research in Information Systems: The Practice of Relevance. MIS Quarterly 23(1), 3-16 (1999)

Cole, R., Purao, S., Rossi, M., Sein, M.K.: Being Proactive: Where Action Research Meets Design Research. In: Avison, D., Galletta, D., DeGross, J.I. (eds.) Proceedings of the 26th International Conference on Information Systems, Las Vegas, pp. 325-336 (2005)

Cross, N.: Understanding Design Cognition. In: Cross, N. (ed.) Designerly Ways of Knowing, pp. 72-95. Birkhäuser, Basel (2007)

Davenport, T.H.: Process Innovation: Reengineering Work Through Information Technology. Harvard Business School Press, Boston (1993)

Davis, R.: Business Process Modeling with ARIS: A Practical Guide. Springer, London (2001)

Davies, I., Green, P., Rosemann, M., Indulska, M., Gallo, S.: How Do Practitioners Use Conceptual Modeling in Practice? Data and Knowledge Engineering 58(3), 358-380 (2006)

Dewey, J.: Human Nature and Conduct. Henry Holt, New York (1922)

Goldkuhl, G.: Design Theories in Information Systems: A Need for Multi-Grounding. Journal of Information Technology Theory and Application 6(2), 59-72 (2004)

Goldkuhl, G., Cronholm, S.: Multi-Grounded Theory: Adding Theoretical Grounding to Grounded Theory. In: Proceedings of the Second European Conference on Research Methods in Business Reading, UK (2003)

Goldkuhl, G., Lind, M.: Coordination and Transformation in Business Processes: Towards an Integrated View. Business Process Management Journal 14(6), 761-777 (2008)

Gregor, S.: The Nature of Theory in Information Systems. MIS Quarterly 30(3), 611-642 (2006)

Gregor, S., Jones, D.: The Anatomy of a Design Theory. Journal of the Association for Information Systems 8(5), 312-335 (2007)

Günther, C., Rinderle-Ma, S., Reichert, M., Van der Aalst, W.M.P., Recker, J.: Using Process Mining to Learn From Process Changes in Evolutionary Systems. International Journal of Business Process Integration and Management 3(1), 61-78 (2008)

Hammer, M.: Reengineering Work: Don't Automate, Obliterate. Harvard Business Review 68(4), 104-112 (1990)

Hanseth, O., Lyytinen, K.: Theorizing about the Design of Information Infrastructures: Design Kernel Theories and Principles. Sprouts: Working Papers on Information Environments, Systems and Organizations 4(12) (2004)

Harmon, P.: The Scope and Evolution of Business Process Management. In: vom Brocke, J., Rosemann, M. (eds.) Handbook on Business Process Management. Springer, Berlin (forthcoming, 2010)

Harrington, H.J.: Business Process Improvement: The Breakthrough Strategy for Total Quality, Productivity and Competitiveness. McGraw-Hill, New York (1991)

Henderson, J.C., Venkatraman, N.: Strategic Alignment: Leveraging Information Technology for Transforming Organizations. IBM System Journal 38(2-3), 472-485 (1999)

Hevner, A.R., March, S.T., Park, J., Ram, S.: Design Science in Information Systems Research. MIS Quarterly 28(1), 75-105 (2004)

Iivari, J., Venable, J.: Action Research and Design Science Research: Seemingly Similar But Decisively Dissimilar. In: Proceedings of the 2009 European Conference on Information Systems, Verona, Italy, June 8-10 (2009)

Keen, P.G.W., Knapp, E.M.: Every Manager's Guide to Business Processes: A Glossary of Key Terms and Concepts for Today's Business Leaders. Harvard Business School Press, Boston (1996) 
Langefors, B.: Theoretical Analysis of Information Systems, 4th edn. Studentlitteratur, Lund (1973)

Lankhorst, M.: Enterprise Architecture at Work: Modeling, Communication, and Analysis. Springer, Berlin (2005)

Lind, M., Albinsson, L., Forsgren, O., Hedman, J.: Integrated Development, Use and Learning in a Co-design Setting: Experiences from the Incremental Deployment of e-Me. In: Cunningham, P., Cunningham, M. (eds.) Expanding the Knowledge Economy: Issues, Applications, Case Studies, pp. 773-780. IOS Press, Amsterdam (2007)

Lind, M., Forsgren, O.: Co-design and Web 2.0: Theoretical Foundations and Application. In: Cunningham, P., Cunningham, M. (eds.) Collaboration and the Knowledge Economy: Issues, Applications, Case Studies, pp. 1105-1112. IOS Press, Amsterdam (2008)

Lind, M., Goldkuhl, G.: The Constituents of Business Interaction: Generic Layered Patterns. Data and Knowledge Engineering 47(3), 327-348 (2003)

Lind, M., Seigerroth, U.: Collaborative Process Modeling: The Intersport Case Study. In: vom Brocke, J., Rosemann, M. (eds.) Handbook on Business Process Management. Springer, Berlin (2010a) (forthcoming)

Lind, M., Seigerroth, U.: A Multi-Layered Approach to Business and IT Alignment. In: Proceedings of the 43rd Hawaii International Conference on System Sciences. IEEE Computer Society Press, Los Alamitos (2010b)

Lind, M., Seigerroth, U., Forsgren, O., Hjalmarsson, A.: Co-design as Social Constructive Pragmatism. Paper presented at the inaugural meeting of the AIS Special Interest Group on Pragmatist IS Research (SIGPrag 2008), Paris (2008)

Lindgren, R., Henfridsson, O., Schultze, U.: Design Principles for Competence Management Systems: A Synthesis of Action Research Study. MIS Quarterly 28(3), 435-472 (2004)

Liu, K., Sun, L., Bennett, K.: Co-Design of Business and IT Systems. Information Systems Frontiers 4(3), 251-256 (2002)

March, S.T., Smith, G.: Design and Natural Science Research on Information Technology. Decision Support Systems 15(4), 251-266 (1995)

Markus, M.L., Majchrzak, A., Gasser, L.: A Design Theory for Systems That Support Emergent Knowledge Processes. MIS Quarterly 26(3), 179-212 (2002)

Mathiassen, L.: Collaborative Practice Research. Information Technology and People 14(1), 321-345 (2002)

Matthews, M.R.: Models in Science and in Science Education: An Introduction. Science and Education 16(7-8), 647-652 (2007)

Nelson, H.G., Stolterman, E.: The Design Way: Intentional Change in an Unpredictable World. Educational Technology Publications, Englewood Cliffs (2003)

Nunamaker, J., Chen, M., Purdin, T.D.M.: Systems Development in Information Systems Research. Journal of Management Information Systems 7(3), 89-106 (1991)

Purao, S.: Design Research in the Technology of Information Systems: Truth or Dare. Unpublished paper, School of Information Sciences and Technology, Pennsylvania State University (2002)

Purao, S., Baldwin, C.Y., Hevner, A., Storey, V.C., Pries-Heje, J., Smith, B.: The Sciences of Design: Observations on an Emerging Field. Working Ppaer No. 09-056. Harvard Business School (2008)

Recker, J.: A Socio-Pragmatic Constructionist Framework for Understanding Quality in Process Modeling. Australiasian Journal of Information Systems 14(2), 43-63 (2007)

Rittgen, P.: Co-designing Models for Enterprises and Information Systems: A Case for Language Integration. In: Magyar, G., Knapp, G., Wojtkowski, W.G., Zupancic, J. (eds.) Advances in Information Systems Development: New Methods and Practice for the Networked Society, vol. 1, pp. 73-83. Springer, Berlin (2007) 
Romme, A.G.L.: Making a Difference: Organization as Design. Organization Science 14(5), 558-573 (2003)

Roseman, M., Vessey, I.: Toward Improving the Relevance of Information Systems Research to Practitioners: The Role of Applicability Checks. MIS Quarterly 32(1), 1-22 (2008)

Rosenblueth, A., Wiener, N.: The Role of Models in Science. Philosophy of Science 12(4), 316-321 (1945)

Scheer, A.-W., Nüttgens, M.: ARIS Architecture and Reference Models for Business Process Management. In: van der Aalst, W.M.P., Desel, J., Oberweis, A. (eds.) Business Process Management. LNCS, vol. 1806, pp. 376-389. Springer, Heidelberg (2000)

Schuette, R., Rotthowe, T.: The Guidelines of Modeling: An Approach to Enhance the Quality in Information Models. In: Ling, T.-W., Ram, S., Li Lee, M. (eds.) ER 1998. LNCS, vol. 1507, pp. 240-254. Springer, Heidelberg (1998)

Searle, J.R.: Speech Acts: An Essay in the Philosophy of Language. Cambridge University Press, London (1969)

Simon, H.A.: The Sciences of the Artificial, 3rd edn. MIT Press, Cambridge (1996)

Stirna, J., Kirikova, M.: How to Support Agile Development Projects with Enterprise Modeling. In: Johannesson, P., Söderström, E. (eds.) Information System engineering: From Data Analysis to Process Networks, pp. 159-185. IGI Publishing, London (2008)

Thomas, O.: Understanding the Term Reference Model in Information Systems Research: History, Literature Analysis and Explanation. In: Kindler, E., Nüttgens, M. (eds.) Business Process Reference Models, Proceedings of the Workshop on Business Process Reference Models, Nancy, France (2005)

Tolvanen, J.-P., Lyytinen, K.: Flexible Method Adaptation in CASE Environments: The Metamodeling Approach. Scandinavian Journal of Information Systems (5), 51-77 (1992)

Van Aken, J.E.: Management Research Based on the Paradigm of the Design Sciences: The

Quest for Field-Tested and Grounded Technological Rules. Journal of Management Studies 41(2), 219-246 (2004)

van der Aalst, W.M.P., Rosemann, M., Dumas, M.: Deadline-Based Escalation in ProcessAware Information Systems. Decision Support Systems 43(2), 492-511 (2007)

Vernadat, F.B.: Enterprise Modeling and Integration (EMI): Current Status and Research

Perspectives. Annual Reviews in Control 26(1), 15-25 (2002)

Vom Brocke, J., Thomas, O.: Reference Modeling for Organizational Change: Applying

Collaborative Techniques for Business Engineering. In: Proceedings of the 12th Americas

Conference on Information Systems, Acapulco, Mexico, pp. 680-688 (2006)

von Wright, G.H.: Explanation and Understanding. Rouledge and Kegan Paul, London (1971)

Walls, J.G., Widmeyer, G.R., El Sawy, O.A.: Building an Information System Design Theory for Vigilant EIS. Information Systems Research 3(1), 36-59 (1992)

\section{About the Authors}

Mikael Lind is an associate professor with the University of Borås, the Viktoria Institute, and Linköping University, Sweden. He is the director of the informatics department and the founder of the InnovationLab at the school of Business and Informatics in Borås. He is also the co-founder of the Swedish GSI (Graduate School of Informatics). He is associated with the research network VITS in Sweden and is active in different international communities such as Language/action and Pragmatic Web. He is also part of the management board for the AIS special interest group SIGPrag (www.sigprag.org). His research focus is on pragmatist IS research on 
co-design of business and IT. The research is divided into four research areas: business process management, e-service innovation, method engineering, and research methods for information systems development. His research is mainly characterized by empirically driven theory and method development, action research, design science, multi-grounded theory, and practical theory. He is also the project manager of the citizen-centric e-service project e-Me - turning the Internet around (www.e-me.se) as well as associate editor for the open journal Systems, Signs \& Actions (www.sysiac.org). He can be contacted by e-mail at mikael.lind@hb.se.

Daniel Rudmark is pursuing his Ph.D. at the InnovationLab, University College of Borås, where he practices modern systems development. He is also a part of the Graduate School of Informatics and the AIS special interest group SIGPrag (www.sigprag.org). Prior to joining University College of Borås, he spent more than 10 years as a developer, architect, project manager, and CTO. His research interests are primarily in the areas of design science in organizational settings and the role of the developer in modern systems development. He is currently involved in two design science research projects and is managing project development activities for the next generation of e-me. He can be contacted by e-mail at daniel.rudmark@hb.se.

Ulf Seigerroth is an assistant professor with Jönköping University, Sweden. Ulf is the co-director and co-founder of CenIT (Centre of Evolving IT in Networked organizations) (www.hj.se/cenit). From 2004 to 2007, he was head of the Department of Informatics. Ulf is one of the co-founders of GSI (Graduate School of Informatics) that was launched in April 2008. He is also part of the AIS special interest group SIGPrag (www.sigprag.org). His current research is directed at issues concerning business and IT-alignment and transformation. Within this area, specific issues of interest are enterprise modeling, enterprise architecture, information logistics, method engineering, co-design, and IT economics. His research is characterized by empirically driven and theory- and method-informed development (action research). $\mathrm{He}$ is involved in different action research projects focusing on alignment of business processes and information systems and information logistics. He can be contacted by e-mail at ulf.seigerroth @ jth.hj.se. 